\title{
sciforum
}

Conference Proceedings Paper

\section{A Lagrangian analysis of the moisture transport during the 2003 drought episode occurred over the Mediterranean region}

\author{
Milica Stojanovic*, Anita Drumond, Raquel Nieto and Luis Gimeno \\ Environmental Physics Laboratory (EPhysLab), Facultade de Ciencias, Universidad de Vigo, Ourense \\ 32004, Spain; smilica@alumnos.uvigo.es (M.S.); anitadru@uvigo.es (A.D.); rnieto@uvigo.es (R.N.); \\ l.gimeno@uvigo.es (L.G.) \\ * Correspondence: smilica@alumnos.uvigo.es; Tel.: +34-988-387-208
}

Academic Editor: Ricardo Trigo

Published: 05/11/2017

\begin{abstract}
In the last decades many studies have pointed out an increasing number of natural hazards associated with extremes in precipitation and droughts over the Mediterranean region. The Mediterranean is located at the border between the tropical climate zone and the mid-latitude climate belt. Due to its large extension and diverse topography, it shows large climatic differences that make its climate scientifically interesting.

The aim of this study is to identify the main climatological moisture sources for Mediterranean region during 1980-2015, and to analyze the moisture transport during the meteorological drought episode observed over the area in 2003. This episode was the most severe in the period 1980-2015 according to the one-month Standardized Precipitation Evapotranspiration Index (SPEI-1) analysis. The SPEI-1 was calculated using monthly Climate Research Unit (CRU TS3.24.01) precipitation (PRE) and potential evapotranspiration (PET). The Mediterranean region was defined according to the 5th Intergovernmental Panel on Climate Change (IPCC) Assessment Report. Analyses of precipitation, potential evapotranspiration, omega at $500 \mathrm{hPa}$, and vertically integrated moisture flux have been conducted to characterize the anomalous patterns over the regions during the episode. A Lagrangian approach was then applied in order to investigate possible changes in the moisture transport over the Mediterranean region during the episode. This approach is based on the FLEXiblePARTicle (FLEXPART) dispersion model integrated with data from the reanalysis produced by the European Centre for Medium-Range Weather Forecasts (ECMWF): the ECMWF Re-Analysis (ERA) - Interim.

Results show that anomalous subsidence, increased PET, and reduced PRE predominated over the region during the episode. The most intensive reduction in the moisture supply for the Mediterranean region was registered from the Mediterranean Sea (MED) source.
\end{abstract}

Keywords: Drought, Mediterranean region, Lagrangian method, SPEI.

\section{Introduction}

Drought is a part of the natural climate cycle that commonly affects large areas and is related to a prolonged lack of precipitation. It starts with a reduction in rainfall (Meteorological drought) and depending on the time, the area on which it extends, intensity and severity, can develop into Agricultural (occurs when there is not enough soil moisture to satisfy the needs of a crop production at a particular time) or Hydrological drought (refers to deficiencies in surface water supply, based on 
The 1st International Electronic Conference on Hydrological Cycle (CHyCle-2017), 12 - 16 November 2017; Sciforum Electronic Conference Series, Vol. 1, 2017

measurements of stream flow and lake, reservoir and groundwater levels) [1-5]. Meteorological drought represents the primary cause of drought, while the other types of drought describe the secondary effects of long-term precipitation deficit on certain sections such as soil moisture, river flows and economic sectors [6].

During the twentieth century, the climate in Mediterranean region has been characterized by an overall temperature increase, and the beginning of the 21st century is marked by intensified severe and prolong drought events [7]. Due to the unique geographic location, the Mediterranean region is particularly vulnerable to the climate variability and the climate change. This region is located in the transition zone between the African climate regime (hot and dry) in South and the European climate (mild and humid) in the North, showing large climate variations [8]. The year 2003 was characterized by one of the worst droughts recorded in Mediterranean region [e.g. 9]. A better understanding of the source-sink relationships in the atmospheric water cycle is very important due to the role that they play in the extreme meteorological events [10].

In this work, our specific objectives are (1) to identify the main climatological moisture sources for the Mediterranean region during the period 1980-2015, by tracking the air masses that eventually reach the region backwards in time through a Lagrangian methodology [11,12], and (2) to analyse the anomalies in the moisture lost over the Mediterranean region during the 2003 meteorological drought episode.

\section{Data and methods}

\subsection{Standardized Precipitation Evapotranspiration Index}

To identify meteorological drought episodes occurred over the Mediterranean region during 1980-2015, we computed the one-month Standardized Precipitation Evapotranspiration Index (SPEI-1). SPEI was first proposed by Vicente-Serrano et al. [13] as an improved drought index that is particularly suitable for studying the effect of global warming on drought severity [14]. The SPEI follows the same conceptual approach like Standardized Precipitation Index (SPI), but rather than concentrating on precipitation alone $[2,15]$, it is based on a monthly climatic water balance (precipitation minus evapotranspiration). SPEI has the advantage of combining multi scalar character with the possibility of including the effects of temperature variability on assessment of drought. It can, therefore, point to anomalies in climatic water balance. The climatic water balance is calculated at various time scales (i.e. accumulation periods), and the resulting values are fit to a log-logistic probability distribution to transform the original values to standardized units that are comparable in space and time and at different SPEI time scales. The index was calculated using the Climate Research Unit (CRU) Time-Series (TS) Version 3.24.01 precipitation (PRE) and potential evapotranspiration (PET) data at a spatial resolution of 0.5 degrees [16]. We have chosen the SPEI-1 time scale which corresponds to the water balance conditions accumulated during one month because this time scale is closely related to meteorological drought [17]. A drought episode starts when the SPEI value falls below zero, followed by a value of -1 or less, and ends when SPEI returns again to positive values $[15,18]$.

\subsection{Lagrangian methodology}

The Lagrangian approach developed by Stohl and James [11,12] was applied to identify the climatological moisture sources during the period 1980-2015 and to analyze anomalies in the moisture lost over the Mediterranean region during the 2003 meteorological drought. The approach is based on the FLEXPART (FLEXiblePARTicle dispersion model), which uses the global reanalysis data ERA-Interim produced by the European Centre for Medium-Range Weather Forecasts (ECMWF). This data set has a horizontal resolution of $1^{\circ}$ on 60 vertical levels, from 1000 to $0.1 \mathrm{hPa}$ [19]. In the FLEXPART simulation, the global atmosphere was divided homogenously into nearly 
The 1st International Electronic Conference on Hydrological Cycle (CHyCle-2017), 12 - 16 November 2017; Sciforum Electronic Conference Series, Vol. 1, 2017

2.0 million particles with constant mass transported using 3D wind fields. The particle position and specific humidity (q) were registered. The changes in specific humidity (q) of each particle along its path were computed every $6 \mathrm{~h}$, and they can be expressed as: $e-p=m(d q / d t)$ where $m$ is the mass of the particle and $e-p$ represents the freshwater flux associated with particle (evaporation $e$ minus precipitation $p$ ). By adding (e-p) for all the particles residing in the atmospheric column over a given area we obtained the total (E-P) field. It represents the surface freshwater flux connected with the tracked particles, where $(\mathrm{E})$ indicates the evaporation rate and $(\mathrm{P})$ indicates the precipitation rate per unit area.

The trajectory of the particles can be traced using a backward in time analysis to determine the sources of moisture for a given region (areas where the particles get moisture $\mathrm{E}-\mathrm{P}>0$ ) or forward in time to identify the sinks of the moisture transported by particles leaving a given region (areas where the particles lost moisture $\mathrm{E}-\mathrm{P}<0$ ). Particles were tracked for a period of 10 days because this is the average residence time of water vapor in the atmosphere [20]. In this study, firstly the trajectories of the particles which reached the Mediterranean region were obtained by backward tracking for the period 1980-2015, and we identified the moisture sources. Then, the trajectories were tracked forwards in time from these sources in order to analyze the anomalies in the moisture supply into the Mediterranean region during the 2003 drought episode.

\section{Results and Discussion}

\subsection{Identification of the major climatological moisture sources for the Mediterranean region during 1980-2015}

To identify the major climatological annual moisture sources for the Mediterranean, we tracked the air masses over the given region backward in time for the period 1980-2015. The Mediterranean region consists only in the land portions shown in the Figure 1 (MED-AR5, grey color), and its boundaries were defined in the $5^{\text {th }}$ Assessment Report (AR5) of the Intergovernmental Panel on Climate Change (IPCC) $[7,21]$. In order to define a threshold that limits the spatial extent of the moisture sources, we used the $95^{\text {th }}$ percentile of the positive values of E-P obtained through the climatology at annual scale. The seven main moisture sources for Mediterranean region according to this threshold of $0.04 \mathrm{~mm}$ /day are shown in Figure 1. Those are: Gulf of Mexico (GMX, garnet color), Gibraltar (GIB, green color), Mediterranean Sea (MED, yellow color), Black Sea (BLS, violet color), Caspian Sea (CPS, cyan color), Terrestrial moisture source region (TER, orange color), and itself. Through the forward in time analysis from these seven sources towards the Mediterranean target region (MED-AR5), climatological results at annual scale reveal that the moisture contribution comes mainly from two sources of moisture: the Mediterranean Sea (MED) and from the own area (MED-AR5). 
The 1st International Electronic Conference on Hydrological Cycle (CHyCle-2017), 12 - 16 November 2017; Sciforum Electronic Conference Series, Vol. 1, 2017

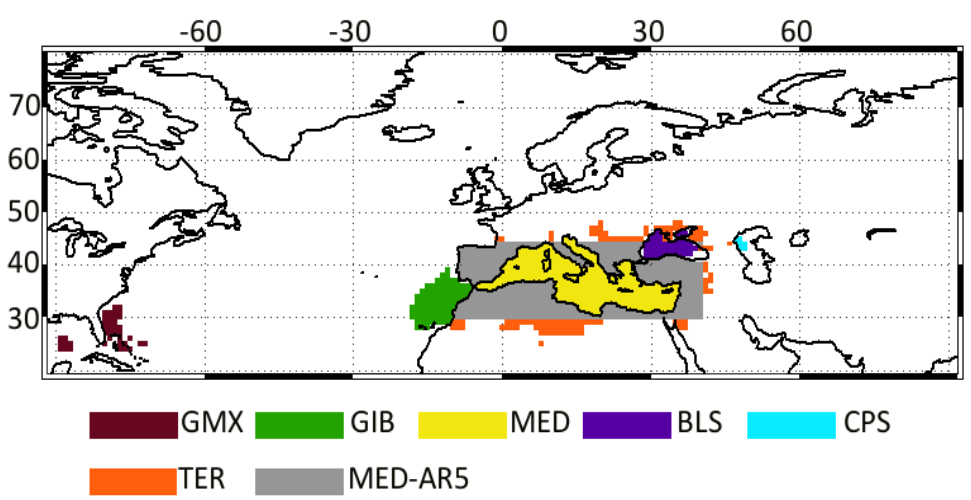

Figure 1. Schematic representation of the main moisture sources for the Mediterranean region (MED-AR5, grey color) at annual scale during 1980-2015: Gulf of Mexico (GMX, garnet color), Gibraltar (GIB, green color), Mediterranean Sea (MED, yellow color), Black Sea (BLS, violet color), Caspian Sea (CPS, cyan color), Terrestrial moisture source region (TER, orange color), and itself.

\subsection{Anomalous patterns configured over the Mediterranean region during the meteorological drought episode of 2003}

The drought occurred over the Mediterranean region in 2003 has been investigated by previous studies [e.g. 22, 23]. This event received considerable attention because it had tremendous adverse social, economic and environmental effects [22].

Through the SPEI-1 analysis over MED-AR5 during 1980-2015, 48 meteorological drought episodes were identified, but the most severe event occurred from May 2003 to August 2003 (4 months). The SPEI-1 values for this episode reached a peak of -2.71 in June 2003, which is associated with the category extreme according to McKee [18].

Monthly anomalies of the PRE, PET, and omega at $500 \mathrm{hPa}$ are shown in Figure 2a, while monthly anomalies of the moisture lost $(\mathrm{E}-\mathrm{P}<0)$ over the MED-AR5 region by the particles leaving the six main sources and itself during the drought episode are shown in Figure $2 b$, together with the precipitation anomalies accumulated (AA-1).

For each month, bars for each source region are set up to avoid cluttering. The height of each color rectangle (computed through the difference between the top and the bottom values of the rectangle reading on the y-axis) represents the magnitude of the anomalous contribution from the respective source. This means that larger color rectangles are associated with a more intensive anomalous contribution. The superimposition of the anomalous moisture lost allows us to estimate the accumulated anomalies in the moisture contribution from all the studied sources in a given month. From the Figure $2 b$ we can see that in May 2003, the onset of the episode, the moisture lost from almost all selected sources reduced (except from the BLS, CPS, and the MED-AR5). In June 2003 (when the SPEI-1 value reached its peak), the moisture contribution from all sources reduced. In July 2003, positive anomalies of moisture contribution prevailed, associated with some weakening in the negative anomaly of precipitation. The drought episode ended in August 2003, associated with positive anomalies of PRE from September onwards. An intensified moisture contribution from the MED and TER sources occurred in September 2003, while in October 2003 this intensification came mainly from MED, GIB and the own region.

The anomalies in the moisture supply by the sources for the MED-AR5 accumulated during the 2003 episode are presented in Table 2, summarizing the effect of each source. In general, a reduction in the moisture supply by the studied sources prevailed during the episode, with the exception of the BLS and TER. Results also indicate that the MED source registered the highest accumulated negative anomalies $(-23.29 \mathrm{~mm} /$ day $)$. 
The 1st International Electronic Conference on Hydrological Cycle (CHyCle-2017), 12 - 16 November 2017;

Sciforum Electronic Conference Series, Vol. 1, 2017

Table 2. Accumulated anomalies of the moisture supply from the sources over the Mediterranean region (MED-AR5) during the drought episode May-August 2003 (in mm/day).

\begin{tabular}{ccccccccc}
\hline Scale & Drought episode & BLS & CPS & GIB & GMX & MED & TER & MED-AR5 \\
\hline SPEI-1 & May - August 2003 & 0.66 & -0.04 & -4.82 & -0.27 & -23.29 & 1.82 & -1.82 \\
\hline
\end{tabular}

Anomalies of the Vertical Integrated Moisture Flux (VIMF) and its divergence are shown on Figure 3 to illustrate the anomalous moisture transport prevailing during the May-August 2003 episode. Divergence of VIMF (reddish color) occurred over the Europe and Mediterranean, indicating the breaking of precipitation over this large spatial domain during the event. An anomalous anticyclonic circulation localized over central Europe confirms the Lagrangian results in terms of the inhibition of the transport of moisture from the MED source towards mainly the northern part of MED-AR5. 
The 1st International Electronic Conference on Hydrological Cycle (CHyCle-2017), 12 - 16 November 2017; Sciforum Electronic Conference Series, Vol. 1, 2017

3

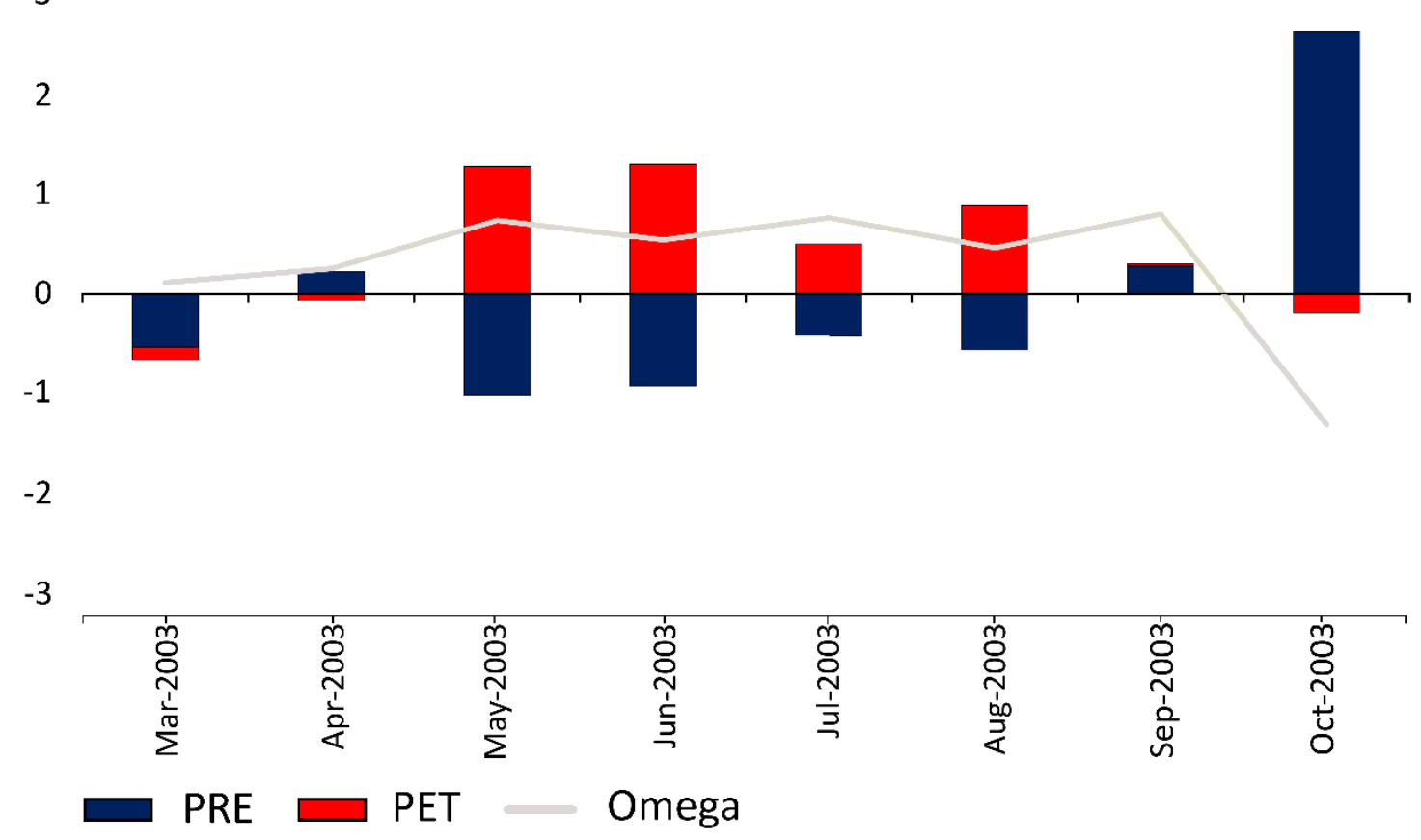

Anomalies of the moisture contribution $(E-P<0)$ from the sources to MED with accumulated anomaly during the drought episode on SPEI-1

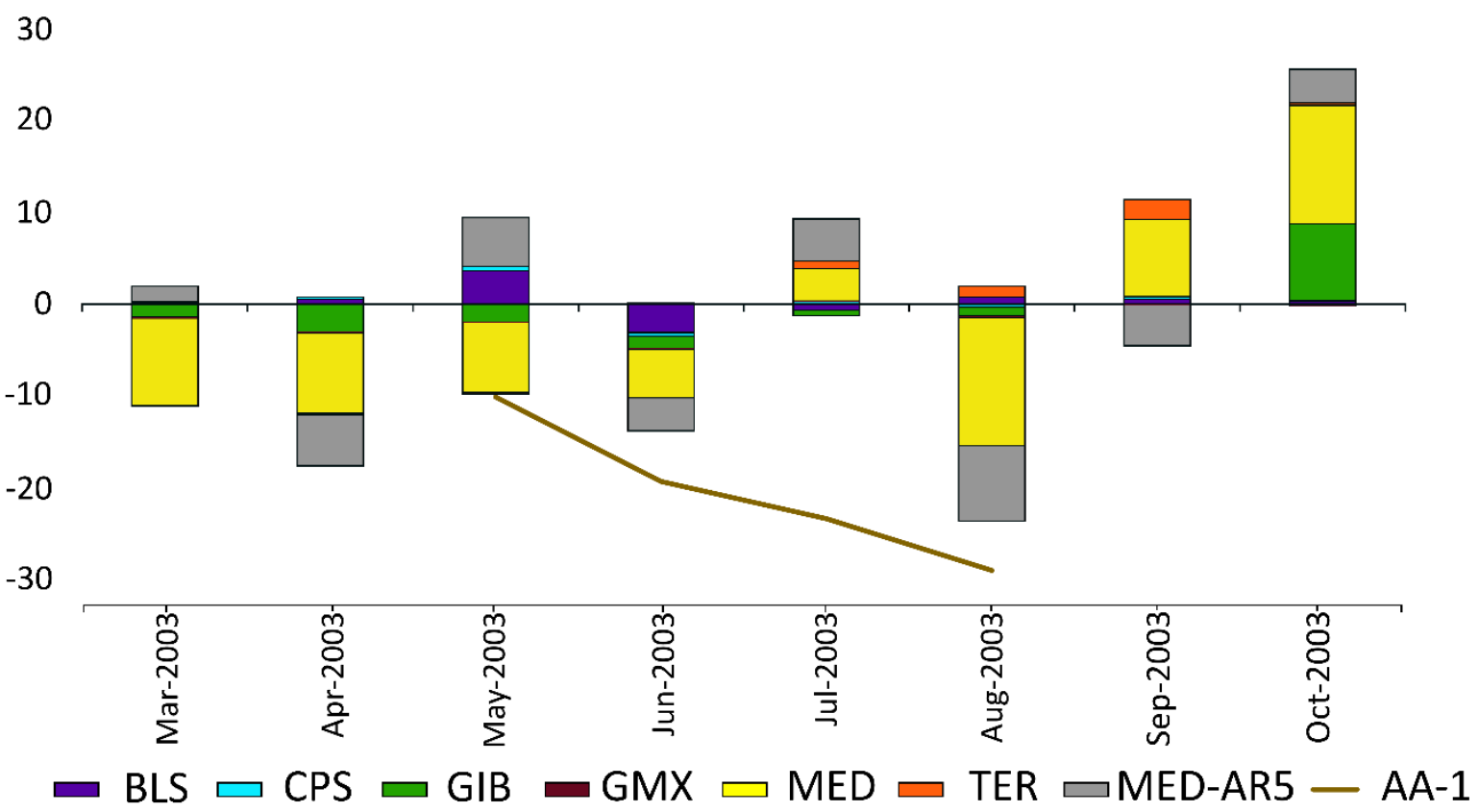

Figure 2. (a) Monthly anomalies of the precipitation (PRE, $x 10 \mathrm{~mm} / \mathrm{month}$, blue bars), potential evapotranspiration (PET, x10 mm/month, red bars) (data from Climatic Research Unit (CRU) Time Series (TS) 3.24.01), and ERA-Interim omega at 500hPa (omega 500, hPa/s, grey line), and (b) Anomalies in the moisture supply $(\mathrm{E}-\mathrm{P}<0)$ (accumulated bars) by each source over the Mediterranean region obtained via the forward experiment $(\mathrm{mm} /$ day) and the accumulated precipitation anomalies (data from CRU TS 3.24.01) (brown line AA-1, mm/month) for the drought episode of 2003. 
The 1st International Electronic Conference on Hydrological Cycle (CHyCle-2017), 12 - 16 November 2017; Sciforum Electronic Conference Series, Vol. 1, 2017

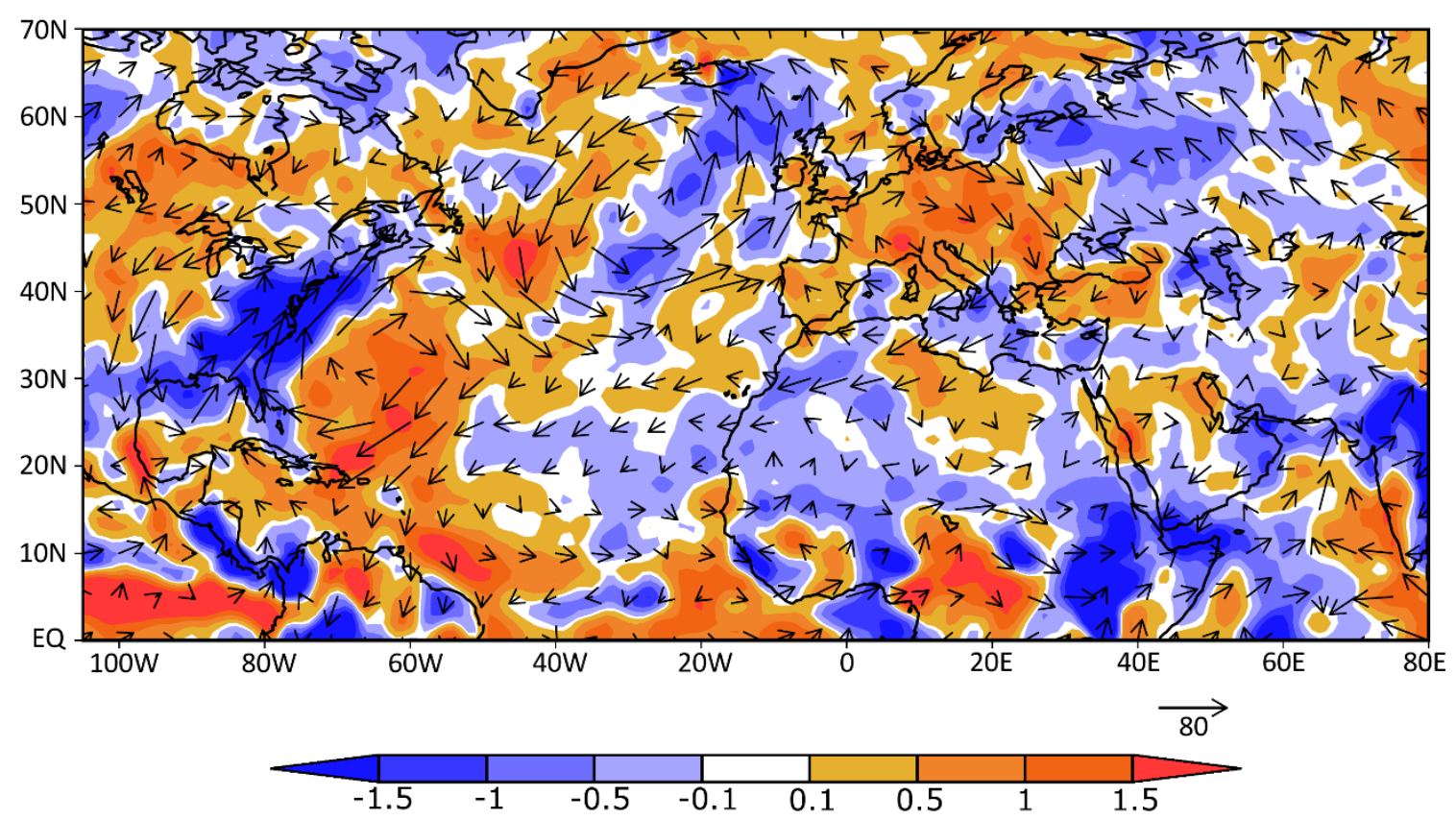

Figure 3. Anomalies of ERA-Interim vertically integrated moisture flux (vector, $\mathrm{kg} / \mathrm{m} / \mathrm{s}$ ) and its divergence (shaded, mm/day) averaged during the May-August 2003 episode.

\section{Conclusions}

In the present study, we investigated the anomalies in the moisture transport observed during the meteorological drought episode occurred over the Mediterranean region in 2003 through a Lagrangian methodology. To do this, we first identified the main climatological moisture sources for the Mediterranean region at annual scale for the period 1980-2015, by tracking the air masses that reach the Mediterranean region backward in time. The Mediterranean region (MED-AR5) mainly receives moisture from seven different oceanic and terrestrial moisture sources regions: Gulf of Mexico (GMX), Gibraltar (GIB), Mediterranean Sea (MED), Black Sea (BLS), Caspian Sea (CPS), Terrestrial moisture source region (TER), and the own region (MED-AR5). The analysis of the Standardized Precipitation Evapotranspiration Index (SPEI) over Med-AR5 revealed that the period May - August 2003 configured the most severe meteorological drought episode in the region during 1980-2015 according to this index calculated in a 1-month scale (SPEI-1).

The 2003 episode was characterized by an anomalous subsidence, increased potential evapotranspiration (PET), and reduced precipitation (PRE) associated with the predominance of reduced moisture supply from almost all the detected moisture sources, with exception of BLS and TER. The Mediterranean Sea (MED), which is the major climatological moisture contributor for MED-AR5, was the source that presented the most intensive reduction in the moisture supply. From September 2003 onwards, the weakening of the anomalous subsidence and of the positive anomalies of PET were associated with an increasing of PRE and a higher moisture supply mainly from MED.

Acknowledgments: Thanks for the funding by the Spanish Government and FEDER through the SETH (CGL2014-60849-JIN) project. M. Stojanovic's Ph.D. fellowship is supported by European Commission under the Erasmus Mundus project Green-Tech-WB: Smart and Green technologies for innovative and sustainable societies in Western Balkans (551984-EM-1-2014-1-ES-ERA Mundus-EMA2). R. Nieto also acknowledges the support of the CNPq Grant 314734/2014-7 by the Brazilian government. We also thank the IMDROFLOOD project financed by the Water Works 2014 co-funded call of the European Commission. 
The 1st International Electronic Conference on Hydrological Cycle (CHyCle-2017), 12 - 16 November 2017; Sciforum Electronic Conference Series, Vol. 1, 2017

Author Contributions: M. Stojanovic, A. Drumond, and L. Gimeno conceived of and designed the experiments. M. Stojanovic performed the experiments and M. Stojanovic, A. Drumond, and L. Gimeno analyzed the data. M. Stojanovic, A. Drumond, R. Nieto, and L. Gimeno wrote the paper.

Conflicts of Interest: The authors declare no conflict of interest. The founding sponsors had no role in the design of the study; in the collection, analyses or interpretation of data; in the writing of the manuscript; nor in the decision to publish the results.

\section{References}

1. Tsiourtis, N. X. (2001). Drought management plans for the Mediterranean region. Report of the water development department. Nicosia, Cyprus. Availble online: http://moi.gov.cy/moa/wdd/wdd.nsf/0/2D42044EF74E0B58C2256EAD00304589/\$file/Pages\%201-19.pd f

2. World Meteorological Organization.Drought Monitoring and Early Warning: Concepts, Progress and Future Challenges.2006. Availble online: http://www.wamis.org/agm/pubs/brochures/WMO1006e.pdf

3. Wilhite, D.A.; Glantz, M.H. Understanding the Drought Phenomenon: The Role of Definitions. Water Int. 1985, 10, 111-120, doi: 10.1080/02508068508686328.

4. Dai, A. Drought under global warming: A review. WIREs: Clim. Change 2010, 2, 45-65, doi:10.1002/wcc.81.

5. Panu, U.S; Sharma, T.C. Challenges in drought research: Some perspectives and future directions.Hydrolog. Sci. J. 2002, 47, S19-S30, doi:10.1080/02626660209493019.

6. Spinoni, J., Naumann, G., Vogt, J., Barbosa, P. 2016. Meteorological Droughts in Europe: Events and Impacts - Past Trends and Future Projections. Publications Office of the European Union, Luxembourg, EUR 27748 EN, doi:10.2788/450449.

7. IPCC, 2014: Summary for Policymakers. In: Climate Change 2014: Mitigation of Climate Change. Contribution of Working Group III to the Fifth Assessment Report of the Intergovernmental Panel on Climate Change [Edenhofer, O., R. Pichs-Madruga, Y. Sokona, E. Farahani, S. Kadner, K. Seyboth, A. Adler, I. Baum, S. Brunner, P. Eickemeier, B. Kriemann, J. Savolainen, S. Schlömer, C. von Stechow, T. Zwickel and J.C. Minx (eds.)]. Cambridge University Press, Cambridge, United Kingdom and New York, NY, USA.

8. Goubanova, K.; Li, L. Extremes in temperature and precipitation around the Mediterranean basin in an ensemble of future climate scenario simulations. Global Planet. Change 2007, 57, 27-42, doi.org/10.1016/j.gloplacha.2006.11.012

9. Levinson, D. H.; Waple, A. M. State of the climate in 2003. Bull. Am. Meteorol. Soc 2004, 85, S1 - S72. doi/pdf/10.1175/BAMS-85-6-Levinson

10. Seneviratne, S.I.; Lüthi, D.; Litschi, M.; Schär, C. Land-atmosphere coupling and climate change in Europe. Nature 2006, 443, 205-209, doi:10.1038/nature05095.

11. Stohl, A.; James, P. A Lagrangian Analysis of the Atmospheric Branch of the Global Water Cycle. Part I: Method Description, Validation, and Demonstration for the August 2002 Flooding in Central Europe. J. Hydrometeorol. 2004, 5, 656-678, doi:10.1175/1525-7541(2004)005. 
The 1st International Electronic Conference on Hydrological Cycle (CHyCle-2017), 12 - 16 November 2017; Sciforum Electronic Conference Series, Vol. 1, 2017

12. Stohl, A.; James, P. A Lagrangian analysis of the atmospheric branch of the global water cycle: Part II Moisture Transports between Earth's Ocean Basins and River Catchments. J. Hydrometeorol. 2005, 6, 961-948, doi:10.1175/JHM470.1.

13. Vicente-Serrano, S.M., Begueria, S., Lopez-Moreno, A.J. A multiscalar drought index sensitive to global warming: The standardized precipitation evapotranspiration index. J. Clim. 2010, 23, 1696-1718, doi:10.1175/2009JCLI2909.1.

14. Vicente-Serrano, S.M., Aguilar, E., Martínez, R., Martín-Hernández, N., Azorin-Molina, C., Sanchez-Lorenzo, A., El Kenawy, A., Tomás-Burguera, M., Moran-Tejeda, E., López-Moreno, J.I., Revuelto, J., Beguería, S., Nieto, J.J., Drumond, A., Gimeno, L., Nieto,R. The complex influence of ENSO on droughts in Ecuador. Clim Dyn. 2017, 48(1-2), 405-427.

15. Tan, C.; Yang, J.; Li, M. Temporal-Spatial Variation of Drought Indicated by SPI and SPEI in Ningxia Hui Autonomous Region, China. Atmosphere 2015, 6, 1399-1421, doi:10.3390/atmos6101399.

16. Harris, I.; Jones, P.D.; Osborn, T.J.; Lister, D.H. Updated high-resolution grids of monthly climatic observations-The CRU TS3.10 Dataset. Int. J. Climatol. 2014, 34, 623-642, doi: 10.1002/joc.3711.

17. Liu, Z.; Lu, G.; He, H.; Wu, Z.; He, J. Anomalous Features of Water Vapor Transport during Severe Summer and Early Fall Droughts in Southwest China. Water 2017, 9, 244, doi:10.3390/w9040244.

18. McKee, T.B.; Doesken, N.J.; Kleist, J. The relationship of drought frequency and duration to time scales. In Proceeding of Eighth Conference on Applied Climatology, Anaheim, CA, USA, 17-22 January 1993; pp. 179-184.

19. Dee, D.P.; Uppala, S.M.; Simmons, A.J.; Berrisford, P.; Poli, P.; Kobayashi, S.; Andrae, U.; Balmaseda, M.A.; Balsamo, G.; Bauer, P.; et al. The ERA-Interim reanalysis: Configuration and performance of the data assimilation system. Q.J. R. Meteorol. Soc. 2001, 137, 553-597, doi:10.1002/qj.828.

20. Numagati, A. Origin and recycling processes of precipitation water over the Eurasian continent: Experiments using an atmospheric general circulation model, J. Geophys. Res., 1999, 104, 1957-1972, doi:10.1029/1998JD200026

21. IPCC, 2013a: Climate Change 2013: The Physical Science Basis. Contribution of Working Group I to the Fifth Assessment Report of the Intergovernmental Panel on Climate Change [Stocker, T.F., D. Qin, G.-K. Plattner, M. Tignor, S.K. Allen, J. Boschung, A. Nauels, Y. Xia, V. Bex, and P.M. Midgley (eds.)]. Cambridge University Press, Cambridge, UK and New York, NY, USA, 1535 pp.

22. Garcia-Herrera, R.; Diaz, J., Trigo, R.M., Luterbacher, J., Fischer, E. M. A review of the European Summer heat wave of 2003. Crit Rev Environ Sci Technol 2010, 40:267-306.

23. Spinoni, J.; Naumann, G.; Vogt, V.V.; Barbosa, P. The biggest drought events in Europe from 1950-2012. J. Hydrol. 2015, 3, 509-524, doi:10.1016/j.ejrh.2015.01.001.

(C) 2017 by the authors; licensee MDPI, Basel, Switzerland. This article is an open access article distributed under the terms and conditions of the Creative Commons by Attribution (CC-BY) license (http://creativecommons.org/licenses/by/4.0/). 